\title{
Sciendo
}

\section{Evaluation and Quality Assurance of teaching: the Evaluation Board in the AVA Process}

\author{
Emanuela Ghiazza \\ Administrative staff, University of Genoa, (Italy) \\ Email: emanuela.ghiazza(anige.it), \\ Luca Salviati \\ Administrative staff, University of Genoa, (Italy) \\ Email: salviati@,unige.it).
}

Doi: $10.2478 /$ gssfj-2020-0002

\begin{abstract}
In this article, we introduce the Evaluation Board (EB-NdV) task in the AVA system (Accreditamento, Valutazione e Auto-valutazione). The AVA was implemented in 2013 in the Italian University System according to the document called "European Standards and Guidelines for Quality Assurance in the European Higher Education Area (ESG)”. The ENQA's guidelines (2005) provide for the construction of a common European area dedicated to university and post-university. In the University, the three main actors involved in the Quality Assurance (QA) system are the Evaluation Board (Nucleo di Valutazione, EB-NdV), the University Quality Board (PQ) and the Joint Student-Teacher Commission (CP). The EB$N d V$ has documented functions of evaluation and monitoring of the $Q A$ system, designed by the PQ following the strategic guidelines of the governing bodies of the university institution. The EB-NdV works as Independent Assessment Body (OIV) too. This task regards the assessment procedures concerning structures and human resources dedicated to the administrative support of the core activities of the universities. The EB$N d V$ draws up an Annual Report related to the $A V A$ system. In conclusion the EB-NdV evaluates the $Q A$ system of the University in its entirety and in all its aspects. Moreover, the EB-NdV evaluates the relationships between the University Quality Board and the Joint Student-Teacher Commission (CP).
\end{abstract}

Keywords: Quality assurance, Higher education 


\section{Introduction}

The harmonization of the various European higher education systems started on June 19, 1999 it is called "Bologna Process". The ministers of 29 European countries met themselves in Bologna to sign an important agreement, the Bologna Declaration, which officially gave the way to this process. The main purpose of this activity is to increase Europe's competitiveness by creating a common higher education area (EHEA). Today the Bologna process has grown to include the wider European area of higher education. This now includes 48 European countries plus the European Commission and numerous members and advisory partners, representatives of public authorities, higher education institutions, associations, quality assurance Agencies, international organizations and other stakeholders. Since 1999, after the alignment of the Italian Study Courses at the European standard $(3+2)$, it has been necessary to introduce the Quality Assurance System (QA).

For "Quality we mean both the value and the degree (level) of the achievement of the objectives (training, research, third mission) established and the fulfilment of the requirements (needs and expectations) for quality (related to teaching, research, third mission) of the University".

The countries participating in the already mentioned harmonization process commissioned the "European Network for Quality Assurance in Higher Education (ENQA)" to design a quality assurance system for universities, in 2003.

At the end of the activity, in 2005, the document "European Standards and Guidelines for Quality Assurance in the European Higher Education Area (ESG)" was produced with the aim of offering support to all university institutions wishing to develop their internal Quality Assurance System.

In 2015 the European system was updated with the publication of the redefined European QA model of higher education, the first version that inspired the Italian model, giving rise to the publication of the new European Guidelines (ESG "Standards and Guidelines in the European Higher Education Area 2015"). The new documentation is based, first of all, on a student-based training system according to the need to combine research and training, the flexibility of training courses and the research for new teaching methods.

\subsection{The Quality Assurance Standards}

The Quality Assurance Standards are declined in three levels: internal, external and certified by recognized external Agencies.

To explain the task of the "Evaluation Board (EB-NdV)" in the QA system, it is necessary to introduce five keywords in order to make easy the comprehension of this topic. The keywords represent the main actors involved in this system:

- Main Academic Bodies: Rector, Board of directors, Academic Senate and General Manager;

- Evaluation Board: Nucleo di Valutazione (EB-NdV-NdV);

- Evaluation experts' committee (CEV): coming from National Agency (ANVUR); 
- The University Quality Board (PQ): internal structure aimed at promoting the cultural quality in the University;

- Joint Student-Teacher Commission (CP): board composed by an equal number of teachers and students.

The European Standards and Guidelines (ESG) in 2015 define that the "Higher education aims to achieve multiple objectives: preparing students for active citizenship and their future career (e.g., contributing to their employability) in order to support their personal development; to create a broad base of advanced knowledge and finally to stimulate research and innovation." For ESG the concept of quality "is not easily definable, but it is basically the product of the interaction between the teachers, the students and the learning context of the Institution. In practice, quality assurance guarantees a learning context in which the content of the Study Courses, the learning opportunities and educational facilities are suitable for this purpose." Moreover, the ESG define that "The various stakeholders, having different priorities, can look at the quality of higher education with different eyes." The term "bearer of interest" refers to all subjects operating inside or outside an institution, that they have an interest in it such as teachers, learners, employees, employers, local institutions and so on.

This is the reason for which the ESG develop different points of attention for the three levels mentioned above.

\subsubsection{The Internal Quality Assurance System}

For what concerns the Internal Quality Assurance System, it is defined in ten points of attention:

- "Quality assurance policy": Universities must adopt a public quality assurance policy that is integrated into their strategic management (stakeholders should develop and implement it through structures and processes).

- "Program design and approval": Universities must have processes for the design and approval of their programs; these processes must be designed in order to achieve specific objectives, including the expected learning objectives.

- "Student-Centred learning, teaching and assessment": Universities must ensure study programs aimed at encouraging students to play an active role in the learning process (this approach must emerge from student evaluation).

- "Student admission, progression, recognition and certification": Universities must apply specific regulations dedicated to all phases of the students' educational path (e.g. admission, progression, recognition and certification of students).

- "Teaching staff": Institutions should ensure the competence of their teachers (fair and transparent procedures for the recruitment and development of staff).

- "Learning resources and student support": Universities should have ade- 
quate financial and instrumental resources both to support learning processes and to support students.

- "Information management": Universities collect and analyse statistical data in order to effectively manage their activities.

- "Public information": Universities must make public information clear, accurate, objective, updated and easily accessible.

- "Continuous monitoring and periodic review of programs": universities must monitor, for the purpose of their review, their own programs to ensure that they achieve the objectives set, thus responding to the needs of students and society (the purpose of this activity is the continuous improvement).

- "Cyclical external quality assurance": Universities must undergo an external quality review in line with the ESG on a cyclical basis.

The Internal Quality Assurance System regards the vision, strategies and policies that university institutions pursue in their two areas of activity (teaching and research). The implemented QA System must be effective for what concerns internal responsibility and information flows between the actors of the quality system to support continuous improvement and to strengthen external responsibility.

\subsubsection{The External Quality Assurance}

For what relates External Quality Assurance the ESG provide seven points of attention:

- "Consideration of Internal Quality Assurance": the external phase of QA must comply with the internal QA processes described above.

- "Designing methodologies suitable for the purpose": the objectives are fixed in order to achieve the (external) quality tasks and the stakeholders are consulted in the design with the aim of continuous process improvement.

- "Implementing processes": the external QA processes must be predefined, reliable, useful, implemented and made public. These processes must include a self-assessment, an external evaluation (including an onsite visit), a report on the results of the external evaluation and adequate follow-up.

- "Peer-review experts": team of experts not belonging to the institution assessed and inclusive students; their activity must be aligned with the requirements of external QA.

- "Criteria" for the results: any results from the external QA must be based on explicit criteria (published) and applied in a coherent matter even if this activity did not result in a formal decision.

- "Reports": the external QA reports approved by the expert teams must be published in an accessible way for their diffusion to the academic community and, more generally, to the University stakeholders. If the relationship has formal consequences, they must be revealed together with the report itself.

- "Complaints and appeals": complaint and appeal processes are an integral 
part of the external QA.

The External Quality Assurance System concerns processes that should be reliable, useful, published according to external criteria that are applied, even if the process does not take to a formal decision or report, but this is important to give the opportunity to the institution to make complaints and appeals that involve the result of the external quality judgment or outcome.

At last, regarding the Quality Assurance certified by external Agencies, the ESG underline the importance of their independence, official status and, at the same time, cyclical external review in seven points:

- Quality assurance activities, policies and processes: agencies must carry out external quality assurance activities (in their activity, agencies must involve stakeholders in the governance of universities).

- Official status: control agencies must be recognized by public authorities.

- Independence: agencies must be independent and autonomous, with full responsibility for their activities.

- Thematic analysis: agencies must make reports describing their external quality assurance activities publicly - on a regular basis.

- Resources: Agencies must have adequate human and financial resources.

- Internal quality assurance and professional conduct: agencies must implement internal insurance processes to qualify their activity.

- External cyclical review of agencies: Agencies must undergo an external review at least once every five years (compliance with the ESG).

In Italy, the agency that supervises the accreditation process of universities is ANVUR. This agency oversees the national public quality assessment system of universities and research institutes, in particular manages the external evaluation of institutions receiving public funds. ANVUR coordinates the activities of the Evaluation Boards $(\mathrm{NdV})$ and finally evaluates the effectiveness and efficiency of public programs aimed at financing and encouraging research and innovation. The ANVUR, on November 14, 2017, requested to undergo the admission procedure to the European Association for Quality Assurance in Higher Education (ENQA) and, at the same time, requested to be included in the European register of quality assurance for higher education (EQAR).

The ENQA Board made the final decision on 20 June 2019 admitting ANVUR as a member of ENQA for the next five years, with a mid-term review by 2021 .

\subsection{The AVA System (Autovalutazione, Valutazione Periodica e Accreditamento)}

The AVA system is the set of QA procedures that Italian universities apply with the aim of continuous improvement of training and research. The AVA system produces information that allows the various actors involved to make informed choices:

- students and families can choose the university that best meets their expectations; 
- companies can identify the most suitable human resources for their recruitment and they can also benefit from the research and development products of the universities;

- universities can evaluate their positioning and plan strategies for the future;

- governments can set their own future policies.

The AVA system provides, first of all, a self-assessment phase for the institution and its structures. This phase consists of a reflection consisting of a complete, systematic and documented analysis of the activities and results of the study courses described in the "SUA-CdS"(Annual Single Card related to Study Courses). The "SUA-CdS" shows the strengths, the weaknesses and the maturity level of the courses. Based on the results of the self-assessment, the Board of the Study Courses may plan corrective or improvement actions. In short, the SUA-CdS module is the annual self-assessment document (containing data and analysis of objectives / results) which refers to a specific academic year together with its SMA (annual monitoring form) which analyses these data. Accreditation, on the other hand, is the process by which a "third party" formally recognizes that an organization has the skills for reaching its tasks. First of all, accreditation guarantees users that the institution can satisfy what they expect of it. The quality assurance system of university education is designed to achieve three main objectives:

- Insurance for MIUR (Ministry of Education, University and Research) and ANVUR users that the country's higher education institutions present the minimum quality level;

- Exercise of responsible and reliable autonomy by universities in the use of public funds and in the collective behaviour of its members;

- Continuous improvement of the quality of research and training activities.

The quality control / accreditation system of university education takes into account the organizational and structural factors, the definition of the expected results, the verification of the actual ones and their correspondence with the external demand for training or research.

The accreditation process includes three phases:

- The documentation for the self-assessment must be prepared by the institution assessed involving all internal actors;

- External evaluation of the self-assessment documentation, carried out by independent experts, also through the on-site visits that must take place according to specific guidelines and conclude with an external evaluation report;

- The release of this report involves the decision on the attribution or revocation of the accreditation.

The Accreditation by the Agency is declined in three different moments: Initial Accreditation, Periodic Accreditation and Periodic Evaluation. ANVUR follows the process in order to measure efficiency, economic and financial sustainability of the Universities' activities. 


\subsubsection{The Initial Accreditation}

The initial accreditation is the authorization - after verification of the requirements set out in Annexes A, B and D of the Ministerial Decree 6/2019) - by the Ministry for the creation of university offices and / or study courses.

The requisites regard didactic, qualification of scientific research, organisation, economic and financial sustainability.

The Annex B to Ministerial Decree 6/2019 establishes the following requirements:

A) Transparency (a complete description about the general organization of the University for what concerns the services for students).

B) Sustainability (financial, logistics, structural, presence of student services including tutoring, significant scientific research activity at international level for at least five years and presence of a QA system organized following the ANVUR indications).

Moreover, in order to achieve the Accreditation of Venues it is necessary to respect some quality requirements (Annex C to DM 6/2019).

These quality requirements are called Requirement 1, 2, 3 and 4 (R1, R2, R3, R4). The first consists in the University's possession of a solid QA system consistent with the institution's strategies; the second concerns the effectiveness of the implementation of this QA system. The third concerns the declination at the level of the course of study of the QA system in terms of design and availability of resources. Finally, the fourth concerns the quality of research and the third mission, or the QA system for these activities must be effective and defined in its guidelines and, the latter, must be pursued by the University and Departments.

The initial accreditation of the study courses requires that they must be established after the initial accreditation itself, which can last no more than three years. In practice, the new courses are established after the initial accreditation which is granted no later than June 15 prior to the academic year of activation, following:

- positive verification of the CUN on the didactic organization;

- verification of the ANVUR of the possession of the requirements set out in Annex A and C (requirement R3) after the first verification work by the Evaluation Board (NdV).

\subsubsection{The Periodic Accreditation}

The Periodic Accreditation consists in checking that what is requested during the initial accreditation persists over time, to this verification it is added the possession of further requirements regarding the efficiency and effectiveness of what has been done using the indicators indicated in Annex C (decree ministerial 6/2019). This analysis is carried out at least every five years for Universities (Venues) and three years for study courses.

For what concerns the accreditation of Venues it regards the Requirements R1, R2 and R4 of Annex C; moreover, the Periodic Accreditation is given to the study courses which present characteristics of alignment with the requirements for initial 
accreditation and with the R3 requirement (Annex C), taking into account the periodic assessment indicators. The verification of these requirements is effected by ANVUR. The test is a remote evaluation based on the documents and the report of the Evaluation Board (NdV).

According to what defined in the previous content ANVUR verification of Study Courses is focused on the following criteria:

- Transparency (a complete general information about the study program including the quality assurance requirements).

- Faculty (the presence of an adequate number of teachers).

- Limits to the fragmentation of individual courses and to the diversification of training courses (e.g. minimum number of CFU assigned to basic and characterizing activities identified in five or six).

- Structures.

- Quality Assurance.

The QA system must be documented for all study courses offered by the University; the latter must prepare all the necessary documentation for quality assurance, including the results of the student opinion survey, the annual compilation of the "SUA-CdS" form and the "SMA" form (attachment A to MD 6/2019).

These documents are useful for the self - evaluation process and for the external ones by the Evaluation Board and by the National Agency. ANVUR analyses on desk this documentation and after on site, when there is the visit of the Evaluation experts' committee (CEV) coming from the National Agency (ANVUR) for the Periodic Accreditation. These documents are the SuA- CdS, the SMA, the Cyclical Review Report and the Annual single cards related to Departments' research (SuA- Rd).

The "SUA-CdS" card is related to each of the courses on offer. This model replaces incorporating the previous ministerial databases and it is also used to plan courses, for the activation / accreditation system and as a communication tool.

The first part, "Quality", presents the following branches:

A - "Training objectives": that is, the training objectives of the study courses, the latter are defined considering both the demand for training by families and students (internal stakeholders), and the demand for skills on the labour market (external stakeholders).

B - "Student experience": that is what students must study, it is indicated in a precise chronological order (i.e. the study plan) as well as the learning environment (services and infrastructures available to them).

C - "Results of training": that is, the statistical data relating to enrolment, career and exit from training for students, as well as the effectiveness of studies with reference to their entry into the world of work.

D - "Organization and quality management": that is, the description of the QA system, both at central level with the University structures (Quality Committee-PQ, Evaluation Board-NdV and Joint Faculty-Students Commission), and at the level of study courses (quality of learning outcomes and quality of educational service). 
The second part - "Administration" - contains information on the general information on the courses (eg contact staff, structures, student representatives, the QA management group, tutors, any limited access and any articulation in curricula). The "SMA" (the annual monitoring form) is the template of which has been defined by ANVUR, it contains indicators on the students' career (quantitative monitoring). The study courses based on these data, draw up an annual monitoring report with a critical comment on the performance achieved in terms of student career, attractiveness, internationalization, employability of graduates, quantity and qualification of teaching staff and graduate satisfaction.

The annual study course monitoring card contains a first section of information which is already contained in the SUA-CdS. These parts are intended to encourage the reading and the comment on the indicators provided by the Agency (these are divided into six sections: "Indicators relating to training", "Indicators of internationalization", "Additional indicators for evaluating the training of Courses", "Indicators relating to training courses study and regularity of careers", "Satisfaction and employability and Coherence and qualification of teaching staff").

The cyclical review report is prepared at multi-year time intervals (depending on the duration of the study courses, the frequency of accreditation and in preparation for a periodic accreditation visit by the Agency). This document underlines the permanence of the validity of the training objectives and of the management system used by the Courses to achieve them. It examines the validity of the training needs on the basis of which the Courses have been designed as well as the professional figures who intend to train them with their skills, the consistency of the learning outcomes pursued by the Courses and the effectiveness of the Course management system.

The Cyclical Review Report verifies, analyses and comments the effects of the corrective actions contained in the previous reports, the current strengths and areas to be improved, the corrective actions on the highlighted critical elements and the changes necessary in order to improve the situation.

The SUA-RD - "Annual single cards related to Departments' research and the third mission" - after the first experimentation, is currently stopped. However, the EBpending the updating of the model - are called to monitor and must verify the documentary activity that the Departments produce for the purposes of planning and organizing research activities and the third mission. In other words, the EB must develop feedback to ANVUR on the production of reference programmatic documents concerning the objectives, resources and management of the Departments on research and the third mission. The third mission can be defined as "the propensity of structures to open up to the socio-economic context, exercised through the enhancement and transfer of knowledge". In effect, the Third Mission involves all the activities with which the universities interact with society in support of traditional activities (first mission teaching in interaction with students and second mission research in synergy with the scientific communities). The Universities, through the Third Mission, come into direct contact with stakeholders and social 
groups. The characteristics of the third mission are multifaceted, so there are several ways in which this activity takes shape. A useful distinction is the following:

"Third mission as economic enhancement of knowledge" which aims to promote economic growth through the transformation of knowledge produced by research into knowledge useful for production purposes (includes the management of intellectual property, the creation of businesses, research on behalf of third parties). "Third mission as third cultural and social mission" consists in proving the well-being of society through cultural content (cultural events, management of museum centres, archaeological excavations, scientific dissemination), social content (public health, community activities), educational content (adult education, lifelong learning, continuing education) or civil awareness content (public debates).

\subsubsection{The Periodic Evaluation}

Periodic Evaluation is aimed at evaluating the efficiency, economic and financial sustainability of the activities and results achieved by the University in its main branches of activity (teaching, research and internationalization) with reference to the indicators of Annex E (Ministerial Decree 6/2019).

For the purposes of the Periodic Evaluation of the Venues, the progress of the indicators of each groups A, B, C and D of Annex E is verified. Based on their strategic planning, the Universities select, at least, one indicator for each area concerning the previous four groups (A - Didactical Indicators, B Internationalization Indicators, C - Qualifying Research at central level, D Economic and Financial sustainability at central level). The Periodic Evaluation of Study Courses is verified by indicators of A, B and E groups ( $E$ - Further didactical indicators). The set of indicators can be updated by the Ministry on the proposal of ANVUR following the results of the experiments conducted (e.g. on the transversal and / or disciplinary competences acquired by the students) and the collection of new data (e.g. relating to the students' opinions and to the III mission activity). For what concerns A group (Didactical Indicators) the focus is on the regularity of studies, the attractiveness, sustainability in terms of percentage ratio regular students / professors, efficiency and teaching staff. Regarding the Internationalization Indicators (B group), the focus is on the international attractiveness and on the outgoing student mobility. The $\mathrm{C}$ group (Qualifying Research at central level) regards the results of the last Research Quality Assessment by ANVUR at central level and at peripheral level (Departments). It refers, in particular, to the Quality Research of $\mathrm{PhD}$ teaching staff, the percentage ratio of the enrolled $\mathrm{PhD}$ students previously graduated in another University and, at last, the percentage ratio of employed professors in the previous year coming from other Universities. The D group (Economic and Financial sustainability at central level) concerns the financial sustainability of the institution and the employers' expenses. The last group (E Further didactical indicators) points out the quality of the teaching staff, the efficiency in terms of percentage ratio of graduates, which would choose the same Study Courses again, and the regularity of study programs. 


\subsection{The actors of the QA System with particular regard to the Eval- uation Board}

The actors of the QA system are the following:

- Main Academic Bodies: Rector, Board of directors, Academic Senate and General Manager;

- The Evaluation Board (EB-NdV);

- The University Quality Board (PQ);

- Teachers-Students Joint Committee (CP);

- Schools (formerly Faculties);

- Departments;

- Study Courses.

The University's QA system provides different levels of responsibility:

- the political and political-administrative summit (rector, board of directors, academic senate and general manager) defines internal policies, including those relating to quality; their task is the drafting of strategic guidelines;

- the PQ, on the other hand, is responsible for planning and implementing these QA policies; in carrying out its activities, the PQ is called upon to follow the strategies defined by the academic summit and it is responsible for quality control, with reference to both planning and implementation.

Therefore, the three main actors of the QA system are:

- The University Quality Board (PQ);

- Teachers-Students Joint Committee (CP);

- The Evaluation Board (EB-NdV).

It is important to remind that the quality control system involves all staff (both didactic and administrative), not only the three main bodies described above.

The PQ is the internal structure of the University which has responsibility for the QA system and its structuring. The PQ, therefore, promotes the culture of quality, it provides advice in the context of QA and, finally, it controls and monitors the University's QA processes. The PQ coordinates the academic bodies and it is responsible for the information flows among the EB-NdV and the other actors. The PQ is responsible for the responsibility of managing quality procedures at the level of peripheral structures of the University both for teaching and research. On the occasion of the periodic accreditation visits by the CEVs, the PQ also acts as a speaker for the University. The work of the PQ is monitored locally by the EB-NdV and, during the accreditation process, by the CEV.

After, an equal number of Professors and Students composes the Teachers-Students Joint Committee (CP); its activities are:

- monitoring of the educational offer including the quality of teachers and the services made available to students;

- the construction of indicators to evaluate the training processes and their results;

- the formulation of opinions on activation / cancellation of courses. 
The CP summarizes its work and it formulates its proposals for improvement in an annual document to be sent to the PQ and to the EB-NdV at the end of the year. The EB-NdV, the next actor in the process, is a body of universities whose tasks are the evaluation and formulation of recommendations. The EB-NDV deals with the evaluation of administrative management, teaching, research and interventions in support of the right to study (in particular it is called, within the procedures for the provision of dedicated funding by the ministry, to express itself on the services for students with disabilities and learning difficulties). The EB-NdV also monitors and evaluates the activity of the PQ in relation to the QA system. The EB-NdV carries out its activities by monitoring, also through comparative cost performance analyses, the correct use of public resources within teaching and research, as well as administrative activities. The law also assigns the functions of the independent assessment body (OIV) to the EB-NdV for the procedures for assessing structures and human resources, in order to "promote merit and improve performance in universities, in full autonomy and with their own organizational and individual methods ". (Legislative Decree 27 October 2009, n.150). The EB-NdV draws up an annual report to be sent to ANVUR and relating to the AVA system.

The EB-NdV is also called by Ministerial Decree 6/2019 to perform a series of functions regarding the accreditation procedures for University sites and Study Courses which are:

- formulate a binding opinion on the possession of the requirements for the initial accreditation of new study courses;

- supervise the functioning of the QA system, supporting ANVUR and MIUR in this activity by monitoring the permanence of the initial and periodic accreditation requirements over time;

- support the University bodies and ANVUR in monitoring the results achieved, using the indicators for the periodic evaluation as a comparison, and helping the University in identifying further indicators for the achievement of the objectives of its strategic plans;

- refer in the annual report about the issues of its functions regarding the previous activities over mentioned.

While the PQ designs and monitors the QA system, the EB-NdV defines the general methodology by evaluating the QA system designed by the PQ. The EB-NdV examines, on a five-year rotation, the study courses and the Departments through the analysis of the results using, when it is necessary and appropriate, the hearings. The EB-NdV checks the implementation of the recommendations formulated by the CEV during the external visit in the Study Courses and in the Departments, and if there are critical elements it has the power to require the drafting of a Cyclical Review Report closer in time. As mentioned above, the EB-NdV drafts an annual evaluation document drawn up in compliance with the guidelines that the Agency prepares every year.

The EB-NdV assesses the compliance of the actions taken by the University with regard to the courses that can be defined as critical, in addition, the EB-NdV encourages the improvement of quality and integrates the Agency's investigation with 
its own independent activity. All this information will be useful to ANVUR in the remote analysis ("on desk") carried out for the extension of the periodic accreditation of study courses. In the annual assessment document prior to the expiry of the first three years from the last periodic accreditation of the University, the EB-NdV refers to the Agency about those Courses defined critical by the CEV and to which the ANVUR has expressed some recommendations or conditions. The annual evaluation document, prepared on the template designed by the national agency underline the actions adopted by the Courses in order to improve their performances and those who did not succeed in accomplishing this duty.

For what concerns documents drafted by the EB-NdV the most important one is the AVA annual report that underlines some important functions in the evaluation, in particular the EB-NdV assesses the organization of QA management at central level (University) and peripheral level (Study Courses and Departments) by analysing their effectiveness and effectiveness, it analyses the interactions between the $\mathrm{CP}$ and the PQ and, finally, provides indications and recommendations.

In 2019, the articulation of the document was divided into three section as established by the ANVUR guidelines: analysis of the University's QA system, analysis of administrative performance in support of institutional activities (only for public universities) and, finally, summary recommendations.

The EB-NdV annual document must be interpreted as an element supporting the QA process and the latest document from the University of Genoa is published on line in the special section of the University web-site dedicated to the EB-NdV (https://unige.it/organi/nucleo.shtml), particularly in the appropriate section for the evaluation documents (https://unige.it/nucleo/documenti_valutazione).

The annual document represents a fundamental element connected to the assessment of the site visit by the CEV, in particular it is useful for the preparation for those universities not yet visited while, for those who have already received the visit, it is a Departments). The Agency does not indicate the criteria for selecting the Courses that will be the subject of hearings, nor the methods with which the listening and dialogue processes will be managed. The EB-NdV will be able to provide details of its activity in its annual document support for the action plan to be implemented following the visit itself.

The University of Genoa is still waiting the results of the Accreditation visit on site by ANVUR (CEV) even if it has already passed one year from the visit itself (19-23 November 2018).

The EB-NdV, beyond the report, has other important functions. Given the particularities of the University, the EB-NdV is called upon to manage an evaluation plan for individual courses in collaboration with the PQ. The purpose of this activity is the gradual improvement of all University QA processes (for Study Courses and The EB-NdV of the University of Genoa has already realized a first plan of hearings for all the 22 Departments and now it is planning to monitor the effects of the evaluation by an online survey that will show what the Departments have implemented, in order to improve their quality and to increase their performances. Another project of the EB-NdV of the University of Genoa is to plan and implement 
a SWOT analysis about Department and Study Courses and a further project is about the hearings for the $\mathrm{PhD}$ Courses too.

Even for what concern the $\mathrm{PhD}$ (Doctoral Courses), it is necessary an external evaluation and Accreditation by the national Agency.

The actors involved in this process are:

- Doctorate Courses (PhD);

- $\quad \mathrm{EB}-\mathrm{NdV}(\mathrm{NdV})$;

- National Agency;

- MIUR.

This year for the Doctoral Courses (PHD) Universities have submitted proposals for the XXXV-cycle Doctoral Courses (academic year 2019-2020), accompanied by the EB-NdV Report, to the Agency which has given the Accreditation in the first months of the year. Now the University is waiting the new proposals by the internal structures (Departments) for the XXXVI cycle.

As mentioned before about the sections of the annual report, the EB-NdV is forced to fulfil a special database created by ANVUR that is composed by different parties; for what concerns the first section (I. Assessment of the Quality System of the University) we have the following structure: first of all the analysis of the QA system at central level (requirements R1 and R2), which is subsequently declined at the level of the study courses (requirement R3) and then move on to the analysis of the QA procedures for research and the third mission (requirement R4); subsequently two others topics constituting essential parts of the system are dealt (hearings and customer surveys administered to students).

For what concerns the Performance evaluation (section II, only for the state Universities) guidelines require a report on the overall functioning of the system of evaluation, transparency and integrity of internal controls, art. 14 c. 4 letter a) D.Lgs.150 / 2009). This year the section has been further simplified, allowing the EB-NdV to draw up a free text following the indications of the 2018 ANVUR guidelines or to complete an analysis sheet with 14 points of attention (the EB-NdV of the University of Genoa has decided to proceed with the second choice).

The final section of the annual document ("Recommendations and suggestions") concludes the analysis; starting from what is set out in the previous sections there are the operational recommendations that the EB-NdV provides to the other actors of the QA system and to ANVUR (this section is useful in order to promote the activity of improvement of the QA system).

In order to give a useful example, we report a summary about recommendations and suggestions of the EB-NdV of the University of Genoa for its annual report 2019.

The EB-NdV points out the following strengths:

- the continuity of the careful action to maintain the centrality of the student, as already pointed out last year;

- the necessary attention and consideration of the figure of the student, as clearly emerges from the presence of important and efficient context services provided to the student community; 
- the constant attention to the promotion and improvement of the internationalization activity, especially appreciable in the last year;

- the high degree of consistency, maturation and integration of the QA procedures for training both at a central level (central structures) and at a peripheral level (Departments and Study Courses). This degree makes all the parts of the academic community bonded by a common feeling about the importance of the QA system;

- the activity of the PQ, ever more careful and effective, with particular regard to the drafting of important guidelines improving the implementation of the QA procedures;

- the strengthening of the implementation of correct procedures for the QA research;

- the strong sense of belonging and dedication of the entire academic community to the institution and the change of attitude, now largely positive, towards the QA system;

- the attention of the University to the inclusion policies of disabled students and those with DSA (specific learning disabilities).

The EB-NdV points out the following areas for improvement:

- the attractiveness of master's degree which, despite having increased in number in recent years, but in many cases these Courses have one lower average of enrolled students, despite of the geographical area of reference;

- the attractiveness of the University to students outside region;

- the methods of consultation with the stakeholders and in some cases their limited typology and / or not complete representativeness of the whole territory on which the University insists;

- $\quad$ even if there is an improvement in the activity of the Teachers-Students Joint Committee (CP) there is still, in some cases, not enough involvement of the student component in the work of the Committee, especially in the drafting of the relative report. This lack of involvement is particularly regarding the analysis and evaluation of the students' opinions survey on teaching and its discussion in the internal structures of the Study Courses;

- while appreciating the starting of QA procedures concerning the third mission (including the preparation of the financial statements of sustainability) the EB-NdV underlines that they have not yet reached a rational structure; the EB-NdV hopes for a progress in this direction;

- the EB-NdV appreciates the activity of standardization of the web sites of the Study Courses with a common template of the University, which results clearly structured and makes the web sites themselves easily accessible. Anyway there are some problems about the continuous updating of the information published online and above all to the absence of an English version;

- the EB-NdV underlines the criticality of accessibility in a transparent way to the survey of the opinions of the students/teachers in a disaggregated way for single teaching. 
With reference to the Performance section, the EB-NdV underlines that the procedure followed for the preparation of the 2019 Integrated Plan complies with the provisions of the System of measurement and assessment of the administrative performances. This Integrated Plan takes care about the update activities assigned to the structures by the strategic and operational objectives of the Three-Year Program 2019-2021 (approved in June 2018 and subsequently updated in January 2019). The objectives of the Integrated Plan, related to the technical administrative activity supporting mission activities and functional objectives, are assigned to one or more structures (Management areas, Schools, Centres, Departments), based on the expected competences from the organization chart and process mapping. In the feedback from ANVUR, the declination of the evaluation of organizational performance for decentralized structures in the Integrated Plan 2019 is recognized as a point of strength for the University of Genoa. The Integrated Plan and the ThreeYear Program (containing the objectives and strategies for the University in compliance with Law 43/2005) are parts of another document, so called Integrated Programming Document since 2018. In conclusion, the Integrated Programming Document provides for each objective, the financial resources (budget) and the indicated human resources specifically expected for its achievement.

In this regard, the Evaluation Board recommends "a systematic integration of economic, financial and budget documents and transparency, to be placed in relation to the strategic objectives of the University, to understand the consistency of the actions planned with the choices and the management achieved results ". Therefore, it expresses appreciation for the planned initiative to envisage, through the verification of the performance cycle, the connection with the economic-financial and budget planning phase, the quality standards of services, transparency and prevention and contrast of corruption.

A further function of the EB-NdV in the Accreditation process is the activation of new Study Courses.

In order to allow the initial accreditation of the new study courses by the National Agency, the EB-NdV checks that they meet the initial accreditation requirements and, if the verification is successful, the EB-NdV draws up a report on these training proposals (this report is inserted in the national database). Finally, what is indicated for the EB-NdV, can be summarized in the Statute of the University of Genoa (Art. 24); the essential elements are contained in seven paragraphs which are described below:

- composition of five people plus one student (two interns are university professors); - the five components are proposed by the Rector and approved by the Academic Senate (the Coordinator is internally elected from among the components external to the University);

- the Coordinator convenes the meetings and coordinates the activities of the College; - the EB-NdV examines the University's activities every year and is called upon to perform any further function that is attributed to it by law or by the Statute;

- EB-NdV sends its annual report to the University bodies;

- the assessed subjects can reasonably request a review of their assessments; 
- EB-NdV members remain in office for no more than three years and they have only one possibility of reconfirmation (two are appointed or confirmed each year, this does not apply to the student representative).In conclusion the EB-NdV is in charge of carrying out, by demonstrating it with appropriate documentary evidence (eg public and / or confidential reports, reports, meetings, hearings), monitoring and evaluation activities on the activities of the QA system which, however, it is designed and managed by the PQ following the guidelines and decisions of the University governing bodies.

\section{Web references}

"Standard e linee guida per l'assicurazione della qualità - Standards and guidelines for quality assurance in the EHEA". Available: http://www.processodibologna.it/standarde-linee-guida-per-lassicurazione-della-qualita-standards-and-guidelines-for-qualityassurance-in-the-ehea/

"Linee Guida ANVUR (ANVUR Guidelines)." Available: https://www.anvur.it/en/homepage/

"Statute of University of Genoa". Available: https://unige.it/regolamenti/. 